Research Article

\title{
Resource Misallocation Threshold for High-Tech Industrial Specialization on Technological Innovation Performance for Pharmaceutical Manufacturing
}

\author{
Lei Liang $\mathbb{D}^{1,2}$ and Zhiyong Fan ${ }^{1}$ \\ ${ }^{1}$ School of Economics and Business Administration, Heilongjiang University, Harbin 150080, China \\ ${ }^{2}$ School of Economics and Management, Harbin Engineering University, Harbin 150001, China \\ Correspondence should be addressed to Lei Liang; lianglei1023@126.com
}

Received 6 March 2020; Revised 16 May 2020; Accepted 11 June 2020; Published 17 July 2020

Academic Editor: Kauko Leiviskä

Copyright (c) 2020 Lei Liang and Zhiyong Fan. This is an open access article distributed under the Creative Commons Attribution License, which permits unrestricted use, distribution, and reproduction in any medium, provided the original work is properly cited.

\begin{abstract}
This paper examines the threshold effect of resource misallocation between specialization and technological innovation performance in the high-tech industry in China. Contrary to the existing literature, this paper applies the static panel threshold model to evaluate the threshold effect of industrial specialization on the innovation performance, including the single threshold effect and double threshold effect. The empirical results shed new light on the topic and signified that high-tech industry specialization has a nonlinear effect on innovation performance and the resource misallocation threshold. This paper unveils a novel, double threshold effect of resource misallocation between industrial specialization and innovation performance. Moreover, the twentyeight regions in China are divided into three types according to a resource misallocation, which unfold the current situation of the resource misallocation in pharmaceutical manufacturing-providing directional guidance for structural reforms of the supply side of pharmaceutical manufacturing in various regions.
\end{abstract}

\section{Introduction}

The report of the 19th National Congress indicated that innovation is the first driving force for development and the strategic support for building a modern economic system. In the new normal background, transforming the economic development model and the economy-from labor-intensive and resource-intensive to technology-intensive and capital-intensive and from factor-driven and investment-driven to innovation-driven-has become an important issue for national economic development. The high-tech industry is a knowledge- and technology-intensive industry, and technological innovation is the internal driving force and fundamental way to transform and upgrade the industrial structure $[1,2]$. The same is true for the improvement of firm performance and competitiveness [3]. With the acceleration of regional economic integration and the improvement of interregional specialization and marketization, industrial agglomeration (characterized by industrial clusters) has become an effective model for developing China's hightech industries. Moreover, cultivating world-class, advanced manufacturing clusters is an important way for China's industry to move to the high end of the global value chain. China has continually formed a manufacturing cluster, represented by the regions such as Beijing-Tianjin-Hebei, Yangtze River Delta, Pearl River Delta, and 114 high-tech industrial development zones.

Furthermore, there has been considerable progress in the relationship between specialization and innovation. This research is mainly based on the new economic theory, economic growth theory, and the externality theory of Marshall [4]. From the existing literature, there is considerable controversy about the research on industrial specialization and innovation. However, there are three main representative views. 
The first view is that industrial specialization has a significant role in promoting technological innovation. For instance, Beaudry and Breschi [5] found positive correlations between industrial specialization and technological innovation through empirical analysis of high-tech industries in Italy and the UK. Du and Li [6] discussed the impact of industrial specialization on industrial product innovation in China from a microlevel. The research confirmed that industrial specialization has a positive effect on the new product output. Moreover, Yang et al. [7], using China's 2005-2012 provincial panel data, studied the impact of gathering the high-tech industry on technological innovation and regional comparison. Empirical analysis shows that-when controlling scientific, technological personnel, funding, foreign direct investment, and institutional innovation-this gathering can promote technological innovation.

The second view is that industrial specialization has a depressing effect on innovation. Combes [8] believed that professional specialization has a significantly negative impact on the innovation output, whether it is in the industrial, service, or high-tech industries. Anderrson et al. [9] studied Swedish data and found that a diversified specialization has an inhibitory effect on the innovation output.

Finally, the third view is that there are certain conditions needed for industrial specialization to impact innovation. When the degree of specialization has a limiting condition, industrial specialization and innovation have no simple linear relationship, which is roughly an "inverted U-shaped" relationship $[10,11]$. When the degree of specialization is low, industrial specialization has a positive effect on innovation, and when the degree of specialization is high, industrial specialization has an inhibitory effect on innovation; when time is the limiting condition, the innovative effect of specialized specialization is U-shaped, and it is converted from inhibition to promotion [12]. When the city size and enterprise scale are the constraints, the smaller the city scale, the greater the impact of specialized specialization on the technological innovation of enterprises, and the impact of diversified specialization on the technological innovation of small enterprises is more obvious. Moreover, financial development plays a significantly positive role in regulating the relationship between industrial specialization and "innovation inertia" [13].

These previous examples indicate that the role of industrial agglomeration on technological innovation may not only follow a simple, linear relationship but also may be affected by regional differences, stages, and other factors. With the deep research on industrial agglomeration-driven innovation, some scholars have attempted to analyze the influence mechanism and the mechanism of industrial specialization on innovation, especially the labor and capital. Marshall [14] proposed three sources of specialization externalities in the industry-professional input sharing, labor market sharing, and knowledge and service spillovers-believing that, within the same industry, aggregating enterprises in the geospatial space facilitates the flow and dissemination of knowledge. This will drive knowledge spillovers and accelerate technological innovation activities.
Since then, there has been a growing body of literature about the mechanism of industrial specialization affecting technological innovation from the aspects of technology spillover, cooperative innovation, technology trade, and innovation network. For instance, Du Debin [15] suggested that industrial gatherings enhance the investment environment of the specialization area and attract the entry of innovative activities, whereas Engel and del-Palacio [16] proposed that innovation specialization can promote the intrinsic flow of talent, capital, information, and other resources. Therefore, capital and labor are important factors for industrial specialization to promote technological innovation.

In recent years, scholars have begun to explore the impact of capital and labor allocation on innovation. Li and Ji pushed the mathematical model of factor market distortion and technological progress and carried out empirical tests. The results show that factor market distortion inhibits technological progress and independent innovation in China [17, 18]. For instance, Dai and Liu established a theoretical model of the effect of factor market distortion on innovation efficiency. Moreover, they also used the provincial panel data of China's high-tech industry from 1997 to 2009 to carry out empirical tests. The results demonstrate that factor market distortion significantly inhibits the improvement of innovation performance and innovation efficiency in high-tech industries [19, 20]. Bai and Zhai empirically studied the impact of capital and labor market distortions on innovation efficiency. The results show that the distortion of the factor market will result in the loss of innovation efficiency. Furthermore, the market innovation efficiency-loss gap caused by labor factor distortion and capital factor distortion is examined based on the counterfactual test [21].

With the expanding research, scholars began to conduct detailed research on industrial agglomeration and resource allocation. Ji et al. explored the resource misallocation effect of industrial specialization and believed that the improvement effect of industrial specialization was mainly achieved by reducing the capital threshold and optimizing the labor structure-formed by industrial specialization, the capital threshold, and the labor structure-through synergy with industrial specialization, which positively affects insufficient capital allocation and excessive labor allocation and strengthens and complements the improvement effect of industrial specialization on resource misallocation [22, 23].

Existing research shows that there is a complex role relationship between industrial agglomeration and technological innovation, not just a simple linear relationship but will be constrained by many factors, such as time, region, and financial development. There are also literature studies that demonstrate the flow of resources brought about by industrial gatherings, which in turn change the allocation of labor and capital. However, few scholars have considered whether the regional resource allocation will restrict the effect of industrial agglomeration driving technological innovation. Some industrial agglomerations reflect the government's consciousness, while others are derived from the spontaneous formation of the market. Therefore, in addition 
to the government's macroinstitutional variables, the market's micromechanism will also affect the relationship between industrial agglomeration and technological innovation. The factor endowment greatly influences the spatial distribution [13]. The problem of labor mismatch caused by imperfect factor markets may affect innovation performance. Specifically, under the influence of the geographical space and the household registration management system, labor factors may not be able to flow freely and without barriers. Under the urban-rural dual economic conditions, they may cause labor market segmentation and labor price distortion, further causing the unreasonable allocation of innovative talent, which in turn may affect technological innovation. At the same time, due to the low degree of marketization in China, mismatches in the capital market are common, and innovation capital cannot achieve market freedom and reasonable allocation, which may ultimately affect technological innovation [24]. Therefore, whether it is industrial agglomeration based on government consciousness or industrial agglomeration with market liberalization, the effect of driving technological innovation may be subject to the degree of resource mismatch.

Accordingly, this study incorporates resource allocation into the research framework and adopts a panel threshold model and, taking pharmaceutical manufacturing as an example, considers the correlation characteristics of industrial agglomeration and innovation performance of resource misallocation. It also examines the performance threshold effect and regional heterogeneity of industrial agglomeration-driven innovation from the perspective of regional resource misallocation. Moreover, this study tries to extend the agglomeration externality to drive innovation development through the method and content. It is of great practical significance to explore the high-tech industry agglomeration strategy and regional heterogeneous resource allocation strategy in the new period.
The remainder of this paper is organized as follows. Section 2 presents the method employed. The results of our analysis are presented in Section 3, and Section 4 concludes the paper while offering extensions for future research.

\section{Method}

We have divided this section into two distinct sections. First, we presented the panel threshold model along with a method for estimating resource misallocation. In the next section, we presented the variable description and data processing.

\subsection{Panel Threshold Model and Resource Misallocation Esti-} mation Method. Hansen [25] proposed a method for the quantitative analysis of threshold panel regression models with individual effects. The specific idea of the method was to select a variable as a threshold variable and divide the regression model into multiple intervals according to the searched threshold. Each interval regression equation was expressed differently, and other sample values were classified according to the interval divided by the threshold. Changes of different interval coefficients are compared after the regression. This method can effectively capture the nonlinear threshold characteristics generated by structural mutations in the economic system and test the significance and authenticity of the threshold, which has good characteristics for the general panel data model [26] and can deal with nonlinear problems more objectively and accurately. Therefore, this paper adopts Hansen's threshold panel effect model with resource misallocation as the threshold variable and establishes the threshold model for the high-tech industrial specialization and innovation performance relationship, single threshold model:

$$
\mathrm{INOV}_{i t}=\alpha_{1} \mathrm{RDP}+\alpha_{2} \mathrm{RDK}_{i t}+\alpha_{3} \mathrm{RDR}_{i t}+\alpha_{4} \mathrm{FDI}_{i t}+\beta_{1} \mathrm{AGGR}_{i t} I\left(\tau_{i t} \leq \gamma\right)+\beta_{2} \mathrm{AGGR}_{i t} I\left(\tau_{i t}>\gamma\right)+\mu_{i}+\varepsilon_{i t} .
$$

Here, $i$ and $t$ represent the province and year, respectively. $\mathrm{INOV}_{i t}$ represents the innovation output of the $i$-region in the $t$-year. $\mathrm{RDP}_{i t}$ and $\mathrm{RDK}_{i t}$ represent the research and development (R\&D) personnel and R\&D expenditure, respectively. FDI $_{i t}$ represents the foreign-funded dependency. $I(\cdot)$ is an indicative function. The inequality in parentheses is 1 if it is true and 0 if it is not. $\alpha$ represents the industrial specialization. $\mathrm{AGGR}_{i t}$ is the threshold-dependent variable and the threshold variable. $\tau_{i t}$ is the resource misallocation index. $\gamma$ is the variable threshold. $\mu_{i}$ is the individual fixed effect, and $\varepsilon_{i t}$ is the random interference term. The multiple threshold panel models are as follows (taking the double threshold as an example):

$$
\begin{aligned}
\mathrm{INOV}_{i t}= & \alpha_{1} \mathrm{RDP}+\alpha_{2} \mathrm{RDK}_{i t}+\alpha_{3} \mathrm{RDR}_{i t}+\alpha_{4} \mathrm{FDI}_{i t}+\beta_{1} \mathrm{AGGR}_{i t} I\left(\tau_{i t} \leq \gamma_{1}\right)+\beta_{2} \mathrm{AGGR}_{i t} I\left(\gamma_{1}<\tau_{i t} \leq \gamma_{2}\right) \\
& +\beta_{3} \mathrm{AGGR}_{i t} I\left(\tau_{i t}>\gamma_{2}\right)+\mu_{i}+\varepsilon_{i t} .
\end{aligned}
$$

Here, $\gamma_{1}$ and $\gamma_{2}$ are the double threshold values of the variables, and other symbols are the same as equation (1).
For threshold estimation, according to Hansen's threshold panel model estimation method and due to the individual fixed effect, the original model is simultaneously 
averaged on both sides, and the original model is subtracted from the time-average model to obtain the model's dispersion form. Then, for the estimated threshold and variable, we tested whether there was a single threshold effect. The original hypothesis $\left(H_{0}: \beta_{1}=\beta_{2}\right)$ suggests that when there was no threshold value, the conditional least squares regression is performed on the premise of processing a given threshold, and the threshold value and other parameters that minimize the sum of the squares of the corresponding residuals are obtained.

"Bootstrap" was used to obtain the significant $p$ value for the significance test. If the $p$ value was small enough, the alternative hypothesis was selected by the test rejection hypothesis, meaning there is a threshold value. With the first threshold value fixed, we used the grid search method to determine a second threshold value, minimize the sum of squared residuals, and then correct the first threshold value to obtain the first threshold, which minimizes the sum of squared residuals [27]. According to the principle of a single threshold, we judged whether the second threshold value was significant. If the original hypothesis that only a single threshold value was rejected, there were at least two threshold values. This was followed by analogy to multiple thresholds.

\subsection{Variable Description and Data Processing}

2.2.1. Interpreted Variables. Innovation performance (INOV): innovation output mainly includes patent output and new product output [28]. The sales revenue of new products directly reflects their commercial value, which reflects both innovation output and market acceptance. Combined with the actual data of China's interprovincial pharmaceutical manufacturing industry, this paper selected the sales revenue of new products in the pharmaceutical manufacturing industry to measure the innovation performance and used the GDP price index to reduce the amount and convert it into a constant price based on data from 2009.

\subsubsection{Explanatory Variables. Industrial specialization} (AGGE): many scholars have divided industrial specialization into specialized specialization and diversified specialization [29]. Among them, the most widely used is the measurement method of the Hirschman-Herfindahl index and the number of employees [30]. However, Xie corrected the Hirschman-Herfindahl index measurement method [11]. This paper only investigates specialized specializations and shows the distribution density of several upstream and downstream enterprises, which produce similar products in a certain region and adopt the measurement method of $\mathrm{Lv}$ Chengchao and Shang [29]:

$$
\mathrm{AGGE}_{i j t}=\frac{\text { inc }_{i j t} / \text { inc }_{i t}}{\text { inc }_{j t} / \text { inc }_{t}} .
$$

Here, inc ${ }_{i j t}$ is the main business income of the $t$-year of the $j$-industry in the $i$-region. inc ${ }_{i t}$ is the main business income of the high-tech industry in the $t$-year, and inc ${ }_{j t}$ is the main business income of the $j$-industry in the $t$-year. inc $c_{t}$ is the main business income of the high-tech industry in the $t$-year.

2.2.3. Threshold Variable: Resource Misallocation ( $\tau$ ). Resource misallocations include capital misallocations and labor misallocations, taking the calculation of the labor misallocation index as an example:

$$
\gamma_{i t}=\frac{1}{1+\tau_{i t}} .
$$

Among them, $\gamma_{i t}$ is the absolute distortion coefficient of labor [31,32], indicating that the resources are relatively undistorted in the actual calculation. Replacing it with a relative distortion of factors,

$$
\hat{\gamma}_{i t}=\frac{L_{i t} / L_{t}}{s_{i t} \beta_{i t} / \beta_{t}} .
$$

Among them, $s_{i t}=p_{i} y_{i} / Y$ represents the ratio of the pharmaceutical manufacturing output to the national pharmaceutical manufacturing output in the $t$-year of region $i$, and $\beta_{t}=\sum_{i=1}^{n} s_{i t} \beta_{i t}$ represents the output-weighted labor contribution value. $L_{i t} / L_{t}$ indicates the actual proportion of the labor force used in the pharmaceutical manufacturing industry in the $t$-year of region $i$, and $s_{i t} \beta_{i t} / \beta_{t}$ is the theoretical proportion of the labor force used in the effective allocation of the labor force in the pharmaceutical manufacturing industry. The ratio of the two reflects the degree of deviation of the actual labor allocation from the theoretically effective resource allocation. When the ratio of the two is 1 , it indicates that the labor allocation in the region is effective compared to the pharmaceutical manufacturing industry in the country; when the ratio is less than 1 , it indicates that the labor cost in the region is high, and the labor allocation is insufficient. However, when the ratio is greater than 1, it indicates that the labor cost in the region is low, and the labor allocation is excessive.

Equations (4) and (5) indicate that to calculate the relative distortion index and misallocation index of capital and labor, the output elasticity of capital and labor must be calculated. For the output elasticity of the two, this paper refers to the practice of Zhao Zhigeng et al. [33, 34], using the Solow residual value for calculations. Suppose the production function is a C-D production function with the same scale return:

$$
Y_{i t}=A K_{i t}^{\alpha} L_{i t}^{\beta} .
$$

In equation (6), $\alpha+\beta=1$. The function takes both logarithms at the same time and assumes that the individual effect $\mu_{i}$ and time effect $v_{t}$ in the model follow the specific form:

$$
\ln \left(\frac{Y_{i t}}{L_{i t}}\right)=\ln A+\alpha \ln \left(\frac{K_{i t}}{L_{i t}}\right)+\mu_{i}+v_{t}+\varepsilon_{i t} .
$$

Output variable $\left(Y_{i t}\right)$ : it is expressed by the main business income of the pharmaceutical manufacturing industry in each region and is calculated as a constant price based on the 2009 fixed asset price index. 
Capital investment $\left(K_{i t}\right)$ : it is expressed by the fixed assets of the pharmaceutical manufacturing industry in each region and is calculated as the constant price based on the 2009 fixed asset price index.

Labor input $\left(L_{i t}\right)$ : it is expressed by the average number of employees in the pharmaceutical industry in each region.

This paper used the panel data of the pharmaceutical manufacturing industry in each province from 2009 to 2016 to regress equation (7) and estimate the elasticity of the pharmaceutical manufacturing capital and the labor output in each province. Given different levels of economic development, scientific, and technological strength in various regions, it is obviously unreasonable to adopt mixed regression to estimate the average output elasticity of the national pharmaceutical manufacturing industry. Therefore, this paper used variable-coefficient models with variable slope and variable intercept to estimate the elasticity of the capital and labor output. Drawing on the research methods of Bai and Liu [35], the least squares dummy variable method (LSDV) in the variable-coefficient model is used to estimate the capital and labor output elasticity of pharmaceutical manufacturing in various regions. The interactions between the individual dummy variables, the other dummy variables, and the explanatory variables of variable coefficients $\left(\ln \left(K_{i t} / L_{i t}\right)\right)$ are introduced in the equation to estimate the output elasticity of each region. The estimated result showed the interaction terms between the provincial dummy variables, the other dummy variables, and the explanatory variables of the variable coefficients are significant. Therefore, it is appropriate to use a variable-coefficient model. After estimating the elasticity of capital output $\alpha_{i t}$, we calculated the elasticity of labor output $\beta_{i t}$. Finally, based on the elasticity of the capital and labor output, we calculated the capital and labor misallocation indices $\tau_{k}$ and $\tau_{l}$ of the pharmaceutical manufacturing industries in various provinces of China.

\subsubsection{Control Variables}

(1) R\&D Personnel (L). We used the full-time equivalent of the regional pharmaceutical manufacturing R\&D personnel.

(2) R\&D Expenditure (K). We used the R\&D expenditure internal expenditure as an evaluation indicator of funds. Accounting for the continuity characteristics of innovation activities, it needs to be processed by the perpetual inventory method [36]. The specific method is as follows:

$$
K_{i t}=\frac{I_{i t}}{P_{i t}}+\left(1-\delta_{t}\right) K_{i, t-1} .
$$

Among them, $K_{i t}$ indicates the R\&D capital stock of the pharmaceutical manufacturing industry in the $t$-year of region $i . I_{i t}$ indicates the current investment input flow index, and $P_{i t}$ indicates the consumer price index (CPI). $\delta_{t}$ indicates the depreciation rate, and the depreciation rate is $\delta_{t}=9.6 \%$. The base period capital stock is estimated by Young's [37] method, which is calculated by dividing the internal costs of the R\&D expenditure in the pharmaceutical manufacturing industry in each region by $10 \%$.

(3) Supporting Facilities (FAC). The formation of industrial specialization depends on the construction of infrastructure facilities in the specialization area. Due to the knowledgeand technology-intensive nature of high-tech industries, this paper selected the number of $\mathrm{R} \& \mathrm{D}$ institutions in each region to measure the regional supporting facilities.

(4) Foreign Direct Investment (FDI). Using foreign direct investment in each region, the exchange rate of US dollars to RMB was used to convert these amounts into RMB, and finally, we used the GDP deflator to calculate this amount into a constant price based on the data from 2009.

In this paper, due to changes in data statistics, only the panel data of twenty-eight provincial-level regions (Tibet, Qinghai, and Xinjiang regions with excessive data missing) from 2009 to 2016 were selected for research. The linear interpolation, based on exponential smoothing, was used to supplement the individual missing data. The raw data of the computational variable like INOV, AGGE, $\tau, L, K, \mathrm{FAC}$, and FDI are mainly derived from the China High Technology Statistical Yearbook, China Science and Technology Statistical Yearbook, China Statistical Yearbook, and the China Research Network.

\section{Empirical Results and Analysis}

3.1. Resource Misallocation Index Calculation Results. According to the method described above, we measured the labor misallocation index of the pharmaceutical manufacturing capital misallocation index for 2009-2016 in various regions of China. An index greater than 0 indicates that, compared to the pharmaceutical manufacturing industries in various regions of the country, the proportion of production factors actually allocated in the region in that year is less than the effective allocation ratio of resources (i.e., too few resources were configured). Conversely, when too many resources are configured, we used the method of Ji Shuhan [14], and the capital and labor misallocation indices were processed in the absolute value. The larger the absolute value, the higher the misallocation. This paper used the arithmetic mean of absolute values of capital and labor misallocation indices to measure the overall resource misallocation index. Due to space limitations, this article only lists the capital and labor misallocation indices of pharmaceutical manufacturing in various regions of China in 2016.

It can be seen from Table 1 that there was certain degree of capital and labor misallocation, especially the degree of capital misallocation in 2009. The degree of capital mismatch presents a significant alleviation from 2009 to 2016, especially in Jilin, Anhui, Jiangxi, Hunan, Guangxi, Shanxi, and Gansu. The shortage of capital allocation has been well alleviated. This shows that, during these seven years, the capital allocation level of the pharmaceutical manufacturing industries in these provinces has been greatly balanced with their development level. In addition to these provinces, the 
remaining regional capital allocation has also experienced small fluctuations. Similarly, the labor allocation has also changed to a certain extent. Fifty percent of the regional labor allocation situation have eased, but there are also fifty percent of the regional labor allocation situation showing a slight deterioration from 2009 to 2016.

Specifically for 2016, there was a certain degree of capital and labor misallocation in the pharmaceutical manufacturing industries in various regions of China. Among them, over $57 \%$ of the regions have overallocated their capital, and close to $43 \%$ of the regions have insufficient capital allocation. Over $64 \%$ of the regions have labor overallocation, $36 \%$ of the regions have insufficient labor allocation, and there are large differences in resource misallocations in different regions. The regions with more serious capital misallocations are Beijing, Jiangsu, Anhui, Jiangxi, and Guangxi. Except for Beijing, which has a negative misallocation, the remaining four regions are positive misallocations, reflecting serious capital misallocation. The areas with more serious labor misallocations are Shanxi, Anhui, Shandong, Guangxi, and Gansu. Except for Shandong, which has a positive misallocation, the rest of the regions had negative misallocations, reflecting a serious surplus of labor allocation.

Examining three major regions (eastern, central, and western regions), the capital misallocation in pharmaceutical manufacturing in most parts of the eastern region is heavier and has negative misallocations, which are excessive capital allocation. Labor misallocation is relatively light, and both are positive misallocations, reflecting insufficient labor allocation. The capital misallocation in the central region is more serious, the labor misallocation is lighter, and the capital misallocation mostly manifests as an insufficient allocation.

The western region presents a serious double misallocation between capital and labor, and both are dominated by negative misallocations, reflecting excess capital and labor allocation. As a key development industry in China, the pharmaceutical industry has focused on cultivating and expanding the eastern region where the pharmaceutical manufacturing industry is relatively developed. It is excessively tilted in fiscal policy and financial policy, resulting in a higher degree of capital allocation in the pharmaceutical manufacturing industry in the eastern region than in pharmaceutical manufacturing at the same time.

The economic level of the eastern region is developing at a high level, and the demand for talents is large. The comprehensive infrastructure construction and perfect medical and educational systems have attracted many highly educated talents at home and abroad. Meanwhile, the free flow of the population has been restrained to a certain extent-due to higher labor costs in the eastern region than the central and western regions and the implementation of stricter population control policies. Compared with the optimal labor allocation required for its current development level, the labor allocation for the pharmaceutical manufacturing in the eastern region is too much.

Interestingly, most of the labor misallocations in the central and western regions are dominated by positive misallocations, meaning the actual labor allocation is greater
TABLE 1: Distortion index and misallocation index of human resources in the pharmaceutical manufacturing industry by region in 2009 and 2016.

\begin{tabular}{|c|c|c|c|c|c|}
\hline \multirow{2}{*}{ Region } & \multicolumn{2}{|c|}{2009} & \multirow{2}{*}{ Region } & \multicolumn{2}{|c|}{2016} \\
\hline & $\tau_{k}$ & $\tau_{l}$ & & $\tau_{k}$ & $\tau_{l}$ \\
\hline Beijing & -1.6714 & 0.1617 & Beijing & -1.0752 & -0.0694 \\
\hline Tianjin & -0.0882 & 0.1667 & Tianjin & -0.6233 & 0.0208 \\
\hline Hebei & 0.2636 & -0.1775 & Hebei & 0.5394 & -0.1214 \\
\hline Shanxi & 1.2480 & -0.5588 & Shanxi & -0.5409 & -0.5442 \\
\hline $\begin{array}{l}\text { Inner } \\
\text { Mongolia }\end{array}$ & 0.1538 & 0.1779 & $\begin{array}{c}\text { Inner } \\
\text { Mongolia }\end{array}$ & -0.6884 & -0.2258 \\
\hline Liaoning & -0.1680 & 0.2994 & Liaoning & -0.7131 & -0.0963 \\
\hline Jilin & 17.5640 & -0.2720 & Jilin & 0.6744 & 0.0429 \\
\hline Heilongjiang & -0.8508 & -0.0777 & Heilongjiang & -0.9718 & -0.2722 \\
\hline Shanghai & -0.8933 & 0.1893 & Shanghai & -0.9588 & 0.0576 \\
\hline Jiang Su & 0.8030 & 0.3094 & Jiang Su & 1.2081 & 0.4626 \\
\hline Zhejiang & -0.9284 & 0.0275 & Zhejiang & -0.8954 & -0.2243 \\
\hline Anhui & 4.3840 & -0.4281 & Anhui & 1.9729 & -0.1590 \\
\hline Fujian & -0.9244 & -0.0449 & Fujian & -0.9183 & -0.2181 \\
\hline Jiangxi & 4.0997 & -0.2044 & Jiangxi & 1.4669 & -0.0813 \\
\hline Shandong & 0.8671 & 0.3509 & Shandong & 0.4360 & 0.3672 \\
\hline Henan & 2.3771 & -0.0795 & Henan & -0.2018 & -0.1185 \\
\hline Hubei & 0.3805 & -0.1945 & Hubei & 0.0372 & -0.1632 \\
\hline Hunan & 3.3757 & 0.1290 & Hunan & 0.3042 & 0.2368 \\
\hline Guangdong & -0.1969 & 0.0334 & Guangdong & -0.6674 & -0.0448 \\
\hline Guangxi & 4.8523 & -0.4081 & Guangxi & 1.0595 & -0.2539 \\
\hline Hainan & -0.9271 & -0.1359 & Hainan & -0.1400 & -0.2159 \\
\hline Chongqing & 0.1345 & -0.2567 & Chongqing & 0.1628 & -0.1458 \\
\hline Sichuan & 0.1434 & -0.0410 & Sichuan & -0.7260 & -0.1139 \\
\hline Guizhou & -0.8799 & -0.0984 & Guizhou & 0.0567 & -0.1880 \\
\hline Yunnan & 0.1648 & -0.0111 & Yunnan & -0.8371 & -0.1804 \\
\hline Shanxi & 7.0908 & -0.2319 & Shanxi & 0.3404 & 0.0002 \\
\hline Gansu & 16.2307 & -0.4236 & Gansu & -0.6822 & -0.4035 \\
\hline Ningxia & -0.6028 & -0.2706 & Ningxia & -0.4805 & -0.3763 \\
\hline
\end{tabular}

than the optimal configuration required for the development of the pharmaceutical manufacturing industry, and the misallocation in the western region is heavier. Although the state has implemented preferential policies for credit and financial subsidies in the central and western regions, for the central region, the rapid development of the pharmaceutical manufacturing industry, coupled with the increasing scientific and technological strength, the rate of capital injection lags behind the development needs of the pharmaceutical manufacturing industry. Furthermore, due to the small population movement barriers in the central region, the flow of human resources in the pharmaceutical manufacturing industry can be more closely followed by a market-based distribution, so the central human resource misallocation is lighter. The western region has a low technical level and imperfect infrastructure. The pharmaceutical manufacturing industry is a weak industry. The demand for capital and labor is small, and the marginal output of capital and labor is small. Therefore, capital and labor are overallocated.

3.2. Model Estimation Results and Analysis. By relying upon the panel data of twenty-eight province-level regions in China from 2009 to 2016, taking the pharmaceutical 
manufacturing industry as the research object and empirically analyzing the resource misallocation threshold effect of industrial specialization on innovation performance, we performed panel threshold analysis using STATA14.0 software in conjunction with the xthreg command developed by Wang Qunyong of Nankai University.

3.2.1. Self-Sampling Test Results, Threshold Estimates, and Confidence Intervals. The variable estimation, significance, and confidence intervals based on the resource misallocation index are shown in Tables 2 and 3. The results suggest that the labor threshold is passed through the test at a significant level of $10 \%$ (rejection without the threshold). At a significant level of $5 \%$, the double threshold passes the test (rejecting only a single threshold hypothesis), and the triple threshold fails the test. Therefore, this paper argues that the role of industrial specialization in innovation performance is related to the resource misallocation index, and there is a double threshold effect.

The resource misallocation index threshold is tested, as shown in Table 4. The double threshold estimates are 0.088 and 0.5222 , the confidence interval of the threshold of 0.088 is between 0.0787 and 0.0922 , and the confidence interval of the threshold of 0.5222 is between 0.5056 and 0.5255 .

3.2.2. Drawing Likelihood Ratio Function Graph. The likelihood ratio function graph of the threshold analysis model allows us to more clearly understand the estimation of the threshold value and the construction process of the confidence interval. As shown in Figures 1 and 2, the 95\% confidence interval of the threshold estimates $(0.088$ and 0.5222 ) in the resource misallocation index-double threshold model represents the threshold estimation interval for all LR statistics at less than a 5\% significant level of the threshold estimate. The null hypothesis in which the value is equal to the true value is accepted in the domain, which is why the accepted threshold is equal to the true value.

\subsubsection{Parameter Estimation Result of the Threshold Panel} Model. The parameter estimation results reflect the statistical relationship between the core explanatory variables and the interpreted variables after the threshold variable is divided into several intervals. The model parameter estimation results are shown in Table 5.

When the resource misallocation index is lower than 0.088 , industrial specialization has a positive effect on innovation performance at a significant level of $1 \%$. However, when the resource misallocation index is between 0.088 and 0.5222 , industrial specialization has no significant positive effect on the innovation performance role, and both the coefficient of elasticity and the index are small. When the human resource misallocation index is greater than 0.5222 , industrial specialization has a significant, positive impact on innovation performance, with a significant level of $5 \%$. Among the control variables, R\&D personnel investment, R\&D capital investment, and R\&D institutions have positive effects on innovation performance under the significant
TABLE 2: Variable descriptive statistics.

\begin{tabular}{lcccc}
\hline Variable & Mean & Std. dev & Min & Max \\
\hline $\ln y$ & 5.8130 & 1.2507 & 1.9460 & 8.4693 \\
$\ln k$ & 12.2661 & 1.174 & 9.4293 & 15.0932 \\
$\ln l$ & 7.7351 & 1.0422 & 4.1059 & 9.8303 \\
$\ln$ fac & 3.9172 & 0.9568 & 1.7918 & 6.3509 \\
$\ln$ fdi & 7.6918 & 1.2595 & 4.5698 & 10.5924 \\
agge & 2.2376 & 1.4795 & 0.2156 & 5.7917 \\
$t$ & 0.5654 & 0.8717 & 0.0388 & 8.9180 \\
\hline
\end{tabular}

TABLE 3: Resource misallocation $(\tau)$ and self-sampling test results.

\begin{tabular}{lccccc}
\hline Threshold & $F$ value & $p$ value & $1 \%$ & $5 \%$ & $10 \%$ \\
\hline Single threshold & $16.75^{*}$ & 0.0633 & 23.2761 & 17.1337 & 14.2749 \\
Double threshold & $16.14^{* *}$ & 0.0367 & 25.4368 & 15,1806 & 13.4536
\end{tabular}

TABLE 4: Resource misallocation $(\tau)$ threshold estimates and confidence intervals.

\begin{tabular}{lcc}
\hline Variable & Threshold estimate & Confidence interval \\
\hline$\hat{\lambda_{1}}$ & $0.5222^{*}$ & {$[0.5056,0.5255]$} \\
$\hat{\lambda_{2}}$ & $0.088^{* *}$ & {$[0.0787,0.0922]$} \\
\hline
\end{tabular}

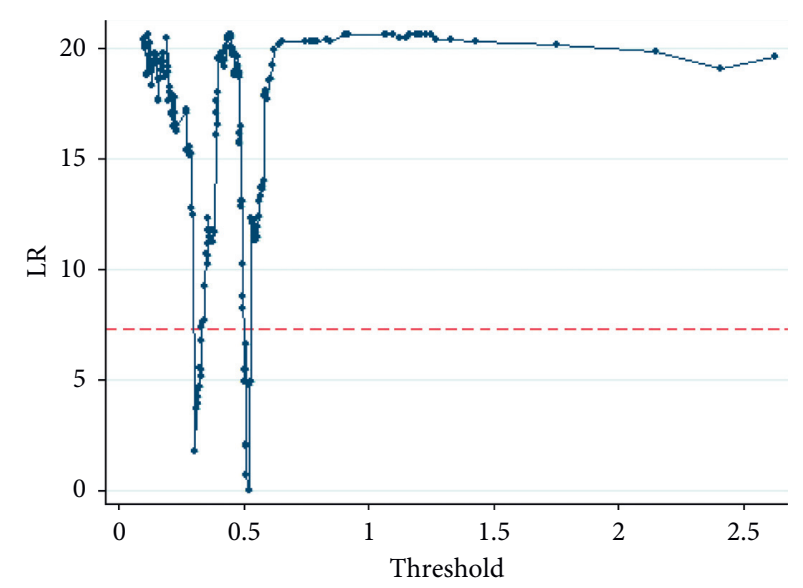

FIgURE 1: The first threshold estimate likelihood ratio function graph of the resource misallocation.

levels of $1 \%, 5 \%$, and $5 \%$, respectively. However, foreign direct investment has an inhibitory effect on the innovation output, and the significant level is $5 \%$.

3.3. Regional Heterogeneity. Based on the threshold effect of the resource misallocation between industrial specialization and innovation output and that the misallocation of pharmaceutical manufacturing resources between different regions is significant, it is necessary to implement differentiated industrial specialization policies according to the degree of resource misallocation in different regions. Specifically, according to the industrial specialization, the resource misallocation thresholds for the innovation output are 0.088 and 0.5222 , and the twenty-eight regions are 


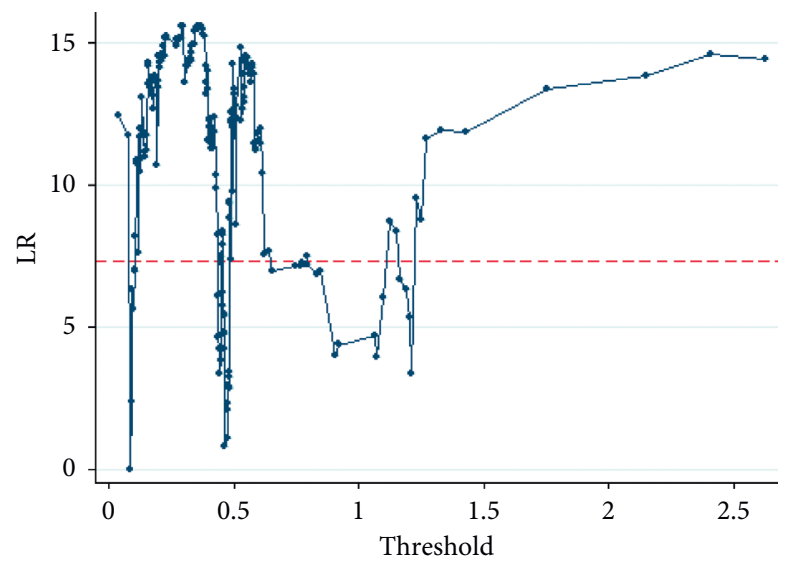

FIgURE 2: The second threshold estimate likelihood ratio function graph of the resource misallocation.

TABLE 5: Resource misallocation $(\tau)$ and double-barrier subsidiary fixed effect regression estimation results.

\begin{tabular}{lcc}
\hline Variable & Regression coefficients & $p$ value \\
\hline $\ln k$ & $1.0464^{* * *}$ & 0.0001 \\
$\ln l$ & $0.1606^{* *}$ & 0.013 \\
$\ln$ fac & $0.5474^{* * *}$ & 0.0001 \\
$\ln$ fdi & $-0.1958^{* *}$ & 0.013 \\
agge $\left(\tau_{i t} \leq 0.088\right)$ & $0.2352^{* * *}$ & 0.003 \\
agge $\left(0.088<\tau_{i t} \leq 0.5222\right)$ & 0.0269 & 0.649 \\
agge $\left(\tau_{i t}>0.5222\right)$ & $0.1426^{* *}$ & 0.019 \\
Cons & $-6.5567^{* *}$ & 0.0001 \\
\hline
\end{tabular}

TABLE 6: Number of different threshold regions.

\begin{tabular}{|c|c|c|c|c|}
\hline \multirow[b]{2}{*}{ Years } & \multicolumn{2}{|c|}{$\tau \leq 0.088$} & \multicolumn{2}{|l|}{$\tau>0.5222$} \\
\hline & Area & Number & Area & Number \\
\hline $\begin{array}{l}2009- \\
2010\end{array}$ & $\begin{array}{l}\text { Hunan, } \\
\text { Yunnan }\end{array}$ & 2 & $\begin{array}{c}\text { Beijing, Shanxi, Jilin, Shanghai, Jiangsu, Anhui, Jiangxi, Shandong, Henan, Hunan, } \\
\text { Guangxi, Hainan, Shanxi, Gansu }\end{array}$ & 14 \\
\hline $\begin{array}{l}2011- \\
2012\end{array}$ & Henan & 1 & Beijing, Shanxi, Heilongjiang, Jiangsu, Anhui, Fujian, Jiangxi, Ningxia & 8 \\
\hline $\begin{array}{l}2013- \\
2014\end{array}$ & - & 0 & Beijing, Heilongjiang, Jiangsu, Zhejiang, Anhui, Fujian, Jiangxi, Ningxia & 8 \\
\hline $\begin{array}{l}2015- \\
2016\end{array}$ & - & 1 & $\begin{array}{c}\text { Beijing, Shanxi, Heilongjiang, Jiangsu, Zhejiang, Anhui, Fujian, Jiangxi, Guangxi, Gansu, } \\
\text { Ningxia }\end{array}$ & 11 \\
\hline
\end{tabular}

The middle resource misallocation regions can be calculated using this table.

divided into three intervals. The misallocation index that is less than 0.088 is the resource misallocation area; [0.088, 0.5222 ] is the medium misallocation area, and the area larger than 0.5222 is the high resource misallocation area. From 2009 to 2016, there were three regions with low resource misallocations in China's twenty-eight regions, accounting for $1.34 \%$ of the total number of samples. Moreover, 153 regions had resource misallocations, accounting for $68.30 \%$ of the total, which indicates that there is a large-scale human resource misallocation in the manufacturing industry. Finally, sixty-eight areas are highly misallocated, accounting for $30.36 \%$ of the total sample, as shown in Table 6 .

As far as the regional dynamic distribution is concerned, the only areas with low resource misallocations in 2009-2016 are the Hunan province, the Henan province, and the Yunnan province. The resource misallocation areas are
Beijing, Shanxi, Jilin, Shanghai, Jiangsu, Anhui, Jiangxi, and eighteen regions including Shandong. From 2009 to 2010, only the Hunan province and the Yunnan province were low misallocation areas, and fourteen areas including Beijing, Shanxi, Jilin, and Shanghai were highly misallocated. In 2011-2012, the low misallocation area was only in the Henan province, and eight areas, including Beijing, Shanxi, Heilongjiang, and Jiangsu, were highly misallocated. Next, in 2013-2014, there were no resource and low misallocation areas, while the high misallocation areas were roughly the same as the high misallocation areas in 2011-2012, Shanxi became a non-high misallocation area, and Zhejiang became a high misallocation area. Finally, 2015-2016 showed high error. The distribution area covers all the high misallocation areas between 2011 and 2014 and has joined Guangxi and Gansu provinces. 


\section{Conclusions}

The goal of China's industrial development is to achieve innovation-driven and move towards the mid-to-high end of the global value chain. Cultivating a world-class advanced manufacturing cluster is an inevitable requirement for achieving this goal in terms of spatial organization and geographic layout. Under the strategic background of national innovation-driven development, this paper uses the provincial panel data of China from 2009 to 2016 and adopts a nonlinear panel threshold model to innovatively introduce resource mismatch into the complex relationship between industrial agglomeration and innovation performance. The significant threshold effect and the regional heterogeneity of resource mismatch have enriched the simple linear relationship between industrial agglomeration and innovation performance in theory and method. Main research conclusions and enlightenment are as follows.

During the period of investigation, various regions of China have different levels of resource mismatch, and the differences between regions are significant. The capital mismatch in most parts of the eastern region is relatively serious and presents a negative mismatch, and the degree of labor mismatch is relatively light. The degree of capital mismatch in the central region is more serious, with a positive mismatch mainly, that is, insufficient capital allocation and light labor mismatch. There are two-way mismatches of capital and labor in the western region, and they are all negative mismatches, and there is an excess of capital and labor. The eastern region has a relatively high level of economic development, strong scientific and technological strength, excessive support for national fiscal policies, and a strong ability to attract investment, resulting in excess capital allocation. In recent years, the pharmaceutical manufacturing industry in the central region has developed rapidly, and its scientific and technological strength has continued to increase. However, the central region's ability to absorb capital is relatively limited, and the level of capital allocation is lower than the optimal allocation for the development of the pharmaceutical manufacturing industry. National key support is urgently needed to promote the rapid development of the pharmaceutical manufacturing in the central region. In the west, the country has implemented the strategy of largescale development and has formulated corresponding preferential policies in various aspects such as policies, projects, capital and talent flow. However, the level of economic development and science and technology in the western region is low, the demand for capital and labor is small, and the actual resource allocation exceeds the optimal allocation level required for its development.

The industrial agglomeration of the pharmaceutical manufacturing industry has a positive promotion effect on innovation performance, but there is a range effect with resource mismatch as a threshold, and the promotion effect varies in different ranges. When the resource mismatch index is low, industrial agglomeration significantly promotes innovation performance at a level of $1 \%$, and the elasticity coefficient is 0.2356 ; when the resource mismatch index is moderate mismatch, industrial agglomeration positively promotes innovation performance, and it is greatly weakened; when the resource mismatch is a high mismatch, the effect of industrial agglomeration on innovation performance changes to a significant promotion effect, with a significant level of $5 \%$ and an elasticity coefficient of 0.1426 . Nearly $68 \%$ of China's regions are in the second interval of resource mismatch, more than $30 \%$ of the regions are in the third interval, and the low mismatch interval accounts for only $1 \%$. Therefore, based on the development needs of the regional pharmaceutical manufacturing industry, continuous optimization of capital and labor allocation and reduction of the resource mismatch index can fully stimulate the positive externality of industrial agglomeration to innovation performance.

In the context of a new round of scientific and technological revolution and industrial transformation, the country deepens the supply-side structural reforms to improve the efficiency of resource allocation, resolve overcapacity, and focus on fostering world-class advanced manufacturing clusters to promote the two ends of Chinese industry's smile curve rising. As far as the actual situation of the pharmaceutical manufacturing industry is concerned, blindly carrying out industrial agglomeration ignoring the degree of mismatch of industrial resources cannot achieve the purpose of quickly driving innovation benefits. To scientifically play the driving role of industrial agglomeration in innovation performance, it is necessary to formulate reasonable industrial agglomeration policies according to local conditions and make full use of other conditions in the regional pharmaceutical manufacturing industry that help drive innovation performance to improve the innovation output, such as increasing R\&D funds and personnel investment and strengthen collaboration with $R \& D$ institutions.

Further research should be conducted to measure the degree of resource misallocation between high-end manufacturing and traditional manufacturing industries and to verify the threshold of the resource misallocation and the negative misallocation of industrial specialization, which drives innovation performance separately. Through followup research on methodology, we can establish a dynamic panel threshold model to demonstrate the dynamic threshold characteristics of the resource misallocation of industrial specialization, which is driving technology innovation.

\section{Data Availability}

The data for the industrial agglomeration and the relevant data of the GDP deflator are available in the China Statistical Yearbook, and all the remaining raw data of the indicators come from the China High Technology Statistical Yearbook.

\section{Conflicts of Interest}

The authors declare that there are no conflicts of interest regarding the publication of this paper. 


\section{Authors' Contributions}

Lei Liang contributed to conceptualization, data collection, calculation, methodology, and writing the original draft. Lei Liang and Zhiyong Fan contributed to reviewing and editing.

\section{Acknowledgments}

This study was supported by Central University Fund "Study on the Key Technology of Military and Civilian Integration and Innovation Resources Sharing Mechanism in High-End Equipment Manufacturing Industry" (3072019CFW0904) and Special Fund Project of Heilongjiang University "Research on the Impact of International Direct Investment on the Upgrading of My Country's High-Tech Industry from the Perspective of Technology Innovation" (HDYJW201906).

\section{References}

[1] H. Park and S. O. Choi, "Digital innovation adoption and its economic impact focused on path analysis at national level," Journal of Open Innovation: Technology, Market, and Complex, vol. 5, no. 3, p. 56, 2019.

[2] K. Shin, E. Kim, and E. Jeong, "Structural relationship and influence between open innovation capacities and performances," Sustainability, vol. 10, no. 8, p. 2787, 2018.

[3] J. Yun, D. Won, E. Jeong, K. Park, D. Lee, and T. Yigitcanlar, "Dismantling of the inverted U-curve of open innovation," Sustainability, vol. 9, no. 8, p. 1423, 2017.

[4] A. Marshall, "“Some aspects of competition." the address of the president of section F-- economic science and statistics--of the British association, at the sixtiet meeting, held at leeds, in september, 1890," Journal of the Royal Statistical Society, vol. 53 , no. 4, pp. 612-643, 1890.

[5] C. Beaudry and S. Breschi, "Are firms in clusters really more innovative?" Economics of Innovation and New Technology, vol. 12, no. 4, pp. 325-342, 2003.

[6] W. J. Du and M. J. Li, “"Does Industrial sets promote enterprise product innovation?-—an empirical study based on Chinese industrial enterprise database," Industrial Economics Research, vol. 4, pp. 1-20, 2015.

[7] H. C. Yang, L. S. Li, and J. Liu, "The influence of high-tech industry clusters on technological innovation and regional comparison," Scientia Research, vol. 34, no. 2, pp. 212-219, 2016.

[8] P. P. Combes, "Economic structure and local growth: France, 1984-1993," Journal of Urban Economics, vol. 47, 2000.

[9] R. Andersson, J. M. Quigley, and M. Wilhelmsson, "Agglomeration and the spatial distribution of creativity," Papers in Regional Science, vol. 84, no. 3, pp. 445-464, 2005.

[10] J. Chen, W. Liang, and H. Wu, "“"Research on the relationship between industrial specialization and innovation performance under the background of open innovation_- taking China's high-tech industry as an example," Science Research, vol. 31, no. 4, pp. 623-629+577, 2013.

[11] Z. Y. Xie, "“'Can regional specialization of high-tech industries improve R\&D efficiency? - an empirical test based on pharmaceutical manufacturing industry," Science Research, vol. 33, no. 2, pp. 215-233, 2015.

[12] Z. Y. Zhang and S. S. Li, "“Research on dynamics and differences of external characteristics of high-tech industry clusters-based on time-varying parameter estimation," Industrial Economics Research, vol. 3, pp. 22-31, 2014.

[13] D. X. Wan and B. Hu, "“Industrial specialization, financial development and "innovation inertiaof enterprises," Industrial Economics Research, vol. 1, pp. 28-38, 2018.

[14] A. Marshall, Principles of Economics, Macmillan \& Co, London, UK, 1920.

[15] D. B. Du, Research on the Location Pattern of R\&D Globalization of Multinational Corporations, Fudan University Press, 2001.

[16] J. S. Engel and I. del-Palacio, "Global clusters of innovation: the case of Israel and silicon valley," California Management Review, vol. 53, no. 2, pp. 27-49, 2011.

[17] P. Li and Y. B. Ji, "Does factor price distortion inhibit China's independent innovation," World Economic Research, vol. 1, pp. 10-15, 2014.

[18] P. Li, Y. B. Ji, and J. W. Sang, "Research on the influence characteristics of factor market distortion on China's technology progress," Industrial Economics Research, vol. 5, pp. 63-71, 2014.

[19] K. Z. Dai and Y. J. Liu, "Factor Market distortion and innovation efficiency-experience analysis of China's high-tech industry development," Economic Research, vol. 51, no. 7, pp. 72-86, 2016.

[20] K. Z. Dai and Y. J. Liu, "How the distortion of factor market affects innovation performance," World Economy, vol. 39, no. 11, pp. 54-79, 2016.

[21] J. H. Bai and Y. C. Zhai, "Factor market distortion and efficiency loss of China's innovative production," China Industrial Economy, vol. 11, pp. 39-55, 2016.

[22] S. H. Ji, Y. M. Zhu, and X. Zhang, "Research on the improvement effect of industrial specialization on resource misallocation," China Industrial Economy, vol. 06, pp. 73-90, 2016.

[23] S. H. Ji and Y. M. Zhu, "A study on resource allocation effect of industrial agglomeration," Quantitative Economic and Technical Economic Research, vol. 34, no. 4, pp. 57-73, 2017.

[24] C. C. Lv and Z. G. Wang, "The mechanism and empirical test of the mismatch of element resources and enterprise innovation-based on the empirical analysis of manufacturing listed companies," Systems Engineering Theory and Practice, vol. 39, no. 5, pp. 1137-1153, 2019.

[25] B. E. Hansen, "Threshold effects in non-dynamic panels: estimation, testing, and inference," Journal of Econometrics, vol. 93, no. 2, pp. 345-368, 1999.

[26] H. P. Liu and T. H. Yan, "The 'threshold effect' in the relationship between OFDI and domestic innovation capability: an empirical analysis from the perspective of regional financial development," Scientific Research Management, vol. 36, no. 1, pp. 1-7, 2015.

[27] J. Bai and P. Perron, "Estimating and testing linear models with multiple structural changes," Econometrica, vol. 66, no. 1, pp. 47-78, 1998.

[28] Y. B. Wu, "China's industrial industry innovation level and influencing factors-an empirical analysis of panel data," Industrial Economic Review, vol. 5, no. 2, pp. 155-171, 2006.

[29] C. C. Lv and Y. Y. Shang, "Research on time and space effect of high-tech industry specialization model and innovation output," Management Science, vol. 30, no. 2, pp. 64-79, 2017.

[30] C. Beaudry and A. Schiffauerova, "Who's right, Marshall or Jacobs? The localization versus urbanization debate," Research Policy, vol. 38, no. 2, pp. 318-337, 2009. 
[31] Y. H. Chen and C. L. Lee, "Factors causing farmland pricevalue distortion and their implications for peri-urban growth management," Sustainability, vol. 10, no. 8, 2018.

[32] M. Yang, F. Yang, and C. Sun, "Factor market distortion correction, resource reallocation and potential productivity gains: an empirical study on China's heavy industry sector," Energy Economics, vol. 69, pp. 270-279, 2018.

[33] Z. G. Zhao, X. L. Liu, and B. Y. Lu, "China's factor output elasticity," Economic Theory and Economic Management, vol. 6, pp. 5-11, 2006.

[34] Z. G. Zhao and C. F. Yang, "Empirical study on the innovation capability of China's high-tech industry during the transition period," China Soft Science, vol. 1, pp. 32-42, 2013.

[35] J. H. Bai and Y. Y. Liu, "Can outward foreign direct investment improve resource misallocation of China," China's Industrial Economy, no. 1, pp. 60-78, 2018.

[36] W. Jie, Z. Zhou, and N. A. Liang, "Measuring the performance of Chinese regional innovation systems with two-stage DEAbased model," International Journal of Sustainable Society, vol. 2, no. 1, p. 85, 2010.

[37] A. Young, "Gold into base metals: productivity growth in the people's Republic of China during the reform period," Journal of Political Economy, vol. 111, no. 6, pp. 1220-1261, 2003. 